\title{
UMA INTERLOCUÇÃO DIREITO DE FAMÍLIA COM A MEDIAÇÃO DE CONFLITOS NO ACESSO À JUSTIÇA
}

\section{Paulo Cuconato}

Mestre em Direito (UNESA/RJ), Pós Graduado em Psicologia Jurídica AVM/UCAM, Mediador Judicial TJ/RJ, Bacharel em Direito e defensor da Paz pela DPRJ/UFF

E-mail: cucopaulo@gmail.com

\section{Dener Martins dos Santos}

Professor Adjunto da UERJ, Professor Doutor do UBM. Pós Doutor e Doutor pela USP, Mestre pela UFF em Engenharia,

E-mail: dener.santos@uerj.br ; dener.martins@ubm.br 


\section{Resumo}

O presente trabalho tem por objetivo apresentar uma abordagem da aplicação da mediação familiar como um veículo no tratamento adequado dos conflitos, em paralelo ao Direito de Família. Contudo, para se mapear a utilização da mediação familiar, primeiramente se fez um levantamento dos principais fatos históricos que marcaram e caracterizaram a implantação da mediação no país, através dos principais eventos legislativos ocorridos; inclusive nos direitos das famílias. Diante disso, se demonstrou que as mediações são mais extensivas nos âmbitos socioafetivos, e não restritivas ao que concerne ao fator patrimonial, que normalmente é o foco principal do direito de família. A partir do exposto, neste trabalho, pôde-se concluir que a implantação da mediação familiar, através do mediador profissional amparado por lei, permitiu que este atuasse como um facilitador e promotor do diálogo, neutro na relação, por estimular a comunicação no processo conflitivo e buscar uma negociação consensuada e benéfica aos envolvidos.

Palavras-chave: Direito de Família, Mediação, Conflitos e Violência Doméstica

\section{Abstract}

The current paper has a purpose to present an approach of mediation on Family Law as a vehicle in the correct treatment of conflicts. However, to map the utilization of family mediation, at first it was performed a survey about the main historical facts that marked and characterized the mediation implantation in the country; through the main legislative events occurred; including in the Family Law . Facing this, it is demonstrated that the mediations are more extensive in the social affective environments and not restrictive ones, related to patrimonial factor, which normally is the main focus of family right. From what was exposed in this essay, it concluded that the implantation of family mediation by a professional mediator supported by law allowed her to act as a facilitator and dialogue promoter, neutral in the relationship, for the communication in the conflict process and searching a consensual and profitable negotiation for the involved parts.

Key words: Family Right, Mediations, conflicts and domestic violence.

\section{Introdução}


Todos os indivíduos originam-se de um núcleo familiar no qual seus aspectos sociais, psicológicos e biológicos se fundamentam. Esse conceito perpetua-se por todos os formatos de famílias, desde a denominada clássica até as demais tipologias de famílias, hoje em dia, jurídica e socialmente aceitas (família: matrimonial, informal, monoparental, substituta e plurais), (GARCIA, 2013). O estudo do direito de família abriga sobre sua égide a normatização de todas as uniões que universalizam a convivência de pessoas na constituição de um lar que estas habitam, sendo a extensão do próprio eu: o casamento, a união estável, o poder familiar (direito parental), os alimentos, a tutela e a curatela (direito assistencial protetivo). De igual forma, o Direito de Família institui as seguintes relações familiares dispostas brevemente em uma tríade: pessoais/afetivas, patrimoniais e assistenciais. Essas relações são protegidas em virtude de interesses maiores, ou seja, a família como "base da sociedade" em conformidade ao que preconiza a Constituição da República Federativa do Brasil de 1988, na inteligência do seu art. 226, caput (CRFB/1988). Em particular, a promulgação da Carta Magna impactou o antigo Código Civil de modo que alterou as bases do Direito de Família. Esse impacto ocasionou um caráter multidisciplinar ao Direito de Família que se refletiu na parte processual, do mesmo e, especificamente, aos institutos da mediação familiar, sendo esta vista e entendida, no presente trabalho, não só como uma porta lateral de acesso à justiça; mas entendida como uma via de acesso central, na prática.

Nos dias de hoje, o Direito de Família brasileiro atravessa dificuldades regulatórias, perante o próprio movimento da evolução social ligado às novas modificações surgidas nas sociedades humanas e suas composições mais tenras. O Direito de Família é um conjunto de normativos e costumes que organizam na sociedade as relações pré e pós-conjugais; pré e pós-parentais; pré e póscolaterais, o que permite a análise das questões de âmbito patrimonial relativas ao objeto do estudo. Nos meados do ano de 2010, aproximadamente, foi promulgado o Novo Código de Processo Civil (NCPC) que teve por quase cinco anos um grande espaço na comunidade jurídica; dentre os muitos movimentos, o auditório público da Corregedoria sediou múltiplos debates nos quais houve vários questionamentos quanto à vacatio Legis, que foi uma das maiores dúvidas ente juristas e operadores do direito.

No ano de 2016, com a reformulação do diploma do Código do Processo Civil, passa a vigorar a Lei 13.105/15. As comissões de juristas organizadores do NCPC tiveram como objetivo fundamental e crônico relacionar a própria morosidade do aparelho judicial e questionaram: "seria justo o emprego desse termo?" - "Seria esta uma verdade una?" - "Como seria a realidade dentro da vivência processualística ao considerar a prática observada na lida entre as partes com seus respectivos advogados, versus a cultura da sentença na qual o objeto 
almejado seria a vingança como uma forma usual?" Como, por exemplo, nas ações de alimentos, como um meio coercitivo estribado na prisão civil, como uma sanção, como uma pena, muitas vezes desejada pelas partes e estas seriam culpadas. - Ou se atribuiria a culpa à morosidade judicial do processo?

Pode-se considerar uma tríade importante dos seguintes institutos, a saber: (i) o excesso da burocracia mais o formalismo presente no Código Civil de 1973; (ii) o modelo atual do NCPC, apresentando uma única defesa de Contestação; (iii) o combate instalado pelo novo diploma do Processo Civil com o excesso de demandas, criando mecanismos para julgá-las mais rapidamente, em blocos, fazendo que sejam resolvidas pelas formas consensuais alternativas no tratamento adequado dos conflitos, a saber: a conciliação, a arbitragem e a mediação, na qualidade de objeto de análise no artigo. Este instituto incorporouse normativamente ao sistema processual como novidades com a Lei Processual 13.105/15 e a Lei da Mediação 13.140/15.

Por fim, a importância do Mediador, unido ao instituto da mediação, como um terceiro imparcial, neutro, objetiva com suas ações capacitadas e técnicas a ampliação e facilitação, ao restabelecer o diálogo entre as pessoas envolvidas, por propiciar resultados benéficos e o tratamento adequado de conflitos. A fim de preservar os laços familiares por respeitar e tratar os envolvidos como autores de suas razões e sentimentos, a cordialidade é um fator indispensável nas ações cujo objeto são os direitos de família, criando a consciência e estimulando a solução adequada às lides e conflitos com maior autonomia, celeridade e independência da figura do juiz.

\section{OBJETIVO}

O objetivo deste trabalho foi demonstrar como a medição pode e deve ser utilizada como veículo condutor e facilitador na interlocução das causas sociais que envolvem o Direito das Famílias, instituto de tratamento adequado na solução dos conflitos, democratização e cidadania; sendo uma das importantes inovações trazidas no NCPC e a Lei da Mediação.

\section{JUSTIFICATIVA}

A mediação e a sua aplicabilidade legal no âmbito familiar passaram a ser disciplinado tanto pelo NCPC quanto pela Lei da Mediação, que determinou uma importante inovação para o legislador nesses últimos anos. Essa criação alternativa na solução de conflitos incentivou o desenvolvimento de técnicas de autocomposição, que se tornaram cada vez mais frequentes. Isso propiciou a positivação das atividades dos mediadores, conforme a previsão legal, o que fortalece mais intensamente a prática adotada no sistema atual, pois, percorrendo todos os seguimentos aplicados à solução de conflitos de um modo 
geral, e no caso deste trabalho, os conflitos familiares, de uma forma menos hierarquizada e adjudicada ao favorecer conforme a natureza da mediação no tecido social.

\section{ANTECEDENTES HISTÓRICOS DA FAMÍLIA ATÉ O CÓDIGO CIVIL} DE 1916

No seio do direito romano, a família era organizada sob o princípio da autoridade. O pater famílias exercia sobre os filhos o direito de vida ou morte (ius vitae ac necis). Assim, era permitido, dispor deles como bem se entendesse, aplicando-lhes castigos e penas corporais, vendê-los e até mesmo matá-los. A figura feminina era restrita e totalmente submissa ao poderio marital, podendo a qualquer momento ser repudiada por ato unilateral do marido.

Mediante o empoderamento investido na figura masculina de autoridade e imperativo, o conceito de família concebido, à época, era simultaneamente classificado como uma unidade religiosa, política, econômica e jurisdicional. Em conformidade a esses valores hierárquicos, o ascendente comum vivo, ora o mais velho, ocupava, em um ínterim, a chefia política, uma posição sacerdotal e até de juiz. A evolução dos tempos abrigou uma diminuição da rigidez, das formas abruptas como eram aplicadas as regras, de acordo até com as necessidades surgidas, como exemplo, a dos militares propiciarem uma criação de patrimônio independente para os filhos. Através do Imperador Constantino, a partir do século IV, foi então inserida no direito romano, uma concepção cristã da família, instalando-se com essa concepção a preocupação fundada predominantemente com a moral. Ao passar dos tempos, paulatinamente, essa evolução se deu no seio da família romana, em uma forma crescente no aspecto inicial em restringir a autoridade do pater, priorizando, então, maior autonomia à mulher e aos filhos, que passaram assim a administrar os vencimentos militares (PEREIRA; 2004).

Na idade Média, as relações de família eram regidas principalmente pelo direito canônico, sendo o casamento religioso o único conhecido. Porém, as normas romanas mantinham perante a sua preponderância, muita influência no que diz respeito ao pátrio poder, bem como nas relações patrimoniais entre os cônjuges. Cabe ainda ressaltar, a influência das regras germânicas que atuaram de forma expansiva. Diante do exposto, é inegável não considerar as influências sofridas pelas famílias brasileiras, conforme a sua definição, delineada na contemporaneidade, oriunda tanto das famílias romanas quanto famílias canônicas e germânicas. É expressivamente forte a manifestação intensa do direito canônico, como consequência, inicial e principal da colonização lusa. A importância das Ordenações Filipinas, como uma fonte vital, trouxe consigo as 
tendências do aludido direito, que por sua vez almejou o direito pátrio (GONÇALVES; 2009).

Dessa forma, nos dias de hoje, mediante as grandes transformações sejam estas históricas, culturais e sociais; o direito de família passou e ainda passa por rumos mais adequados e adaptativos às consequentes transformações da realidade, diminuindo cada vez mais o perfil do direito canônico, dogmático e imbatível, realçando a natureza contratualista, num equilíbrio de ações pertinentes a liberdade de se manter ou não o casamento. (RIZZARDO; 2004).

No caminhar de toda a história familiar, estão presentes muitos e diversos conflitos, tensões que podem se apresentar desde formas latentes ou até em manifestos mais expressivos. O modo de como se deve lidar com tais ocorrências, assumiram bases em uma visão arcaica, ou seja, do pai como um fiscal da mulher, dentro de um modelo tradicional de convivência. $E$ de formas autoritárias, intolerantes, nos quais se mostraram bem proeminentes os relacionamentos opressores e o silenciamento dos mais dependentes e frágeis, como as crianças. Dessa problemática instalada, teríamos outra forma de atuação? Qual o papel da mediação familiar e a sua importância? Poderíamos considerar de uma maneira democrática e respeitosa, os aspectos valorativos da crise no modo de atender as dificuldades encontradas? Ou por outro lado, seriam estas provenientes da busca do entendimento articulado das contradições e duplicidades afetivas do próprio indivíduo? Estariam estas negativamente quedadas por impulsos destrutivos? Como seria a interpretação da busca pela verdade real versus a intersubjetividade da Psicologia? E, por fim, como se lidar com a solução desses conflitos mediante tal problemática?

Segundo Duarte (2012), ao continuar na interlocução mais além, no campo da sociologia, conforme a metodologia da socióloga Denise Duarte Brunno, haveria características pertinentes à organização da família moderna nuclear, ou seja, pai, mãe e filhos, que se dá em razão do amor romântico, surgido da livre escolha dos cônjuges, não se tratando dos interesses dos grupos em perpetuarem vínculos e alianças. Outra característica dessa família consistiria no uso em um espaço privado e íntimo, como um refúgio das pressões do mundo público. Logo, o aconchego familiar então se distinguiria do espaço público. Nos tempos de hoje, observa-se um desequilíbrio em relação ao exercício da autoridade no contexto familiar. Se no passado era o homem como detentor maior da autoridade, hoje, a mulher toma para si as maiores decisões, desde o âmbito doméstico até o trabalho. Certamente, a sociedade já apresenta os efeitos desse momento de transição na história familiar. No ocidente, a organização jurídica da família se iniciou em decorrência da estrutura do Código Civil francês de 1804, conhecido também como Código napoleônico. A família romana foi à responsável pelas bases e modelos de organização patriarcal de todo o ocidente 
e serviu de referência na sua composição jurídica. No caso do Brasil, a lei referencial do modelo de família é de 1916, quando então se instituiu o Código Civil Brasileiro.

\section{Fundamentação Teórica}

\section{A INSTITUIÇÃO FAMILIAR E O DIREITO APÓS A CONSTITUIÇÃO DE 1988}

A edificação dos conceitos jurídicos que norteiam as bases familiares está alicerçada no conjunto de ações em que imperam a harmonia, afeições, segurança e que transmita proteção e abrigo, além de promover a resolução de dilemas, conflitos e bem-estar aos seus membros, bem como nas questões patrimoniais reflexas. Diante desse conjunto de características, a instituição da família toma papel importante na construção da personalidade de cada indivíduo enquanto pessoa humana, capaz de interpretar e garantir a si, aos demais membros da família e à sociedade, a manutenção dos Direitos Civis preconizados na Carta Magna.

Atualmente, a instituição familiar toma uma nova dimensão, pois esta não é estática; e novos conceitos e tipologias estão tomando papel importante na construção da sociedade contemporânea. O papel da família na formação do indivíduo, sob o manto jurídico da Lei, imbui um conjunto de valores, obrigações e deveres capazes de garantir os princípios morais, éticos e a respeitabilidade aos direitos individuais e coletivos. Outro fato relevante é que o modo de vida das pessoas de um determinado extrato da população influi conceitos e valores na formação do indivíduo. Diante disso, vários núcleos específicos podem coabitar regiões características ou existirem mesclados. Contudo, regras universais de convivência devem ser respeitadas, independentemente de sua origem. De acordo com Émile Durkheim não se pode viver em uma sociedade anômica, desorganizada e com ausência de princípios sociais.

Dentre os diferentes tipos de relações de aliança cultural familiar, na formação do indivíduo, exemplifica-se a família nuclear burguesa, na qual esta é disposta na seguinte triangulação: sexualidade, casamento e reprodução. A modelo família nuclear burguesa alicerça-se na coexistência de valores materiais e nos discursos tradicionais. Esse modelo declinou aquele patriarcal diante do direito romano, cuja autoridade absoluta do soberano era imperiosa.

Hoje em dia, há um questionamento mediante a essa queda histórica, que representa o pátrio poder, através da própria emancipação da mulher, perante os fatores de dominação do homem e a autoridade da família inerente ao aumento do empoderamento da mulher como sendo a cuidadora da família. Essa triangulação das relações pessoais contemporâneas envolveu a sexualidade, o 
casamento, e a reprodução diante da perda efetiva do poder de autoridade do homem como detentor pleno do pátrio poder. Nessas relações conflituosas, existem tensões entre a criança como um sujeito de direito e primaz da escuta total a ponto de fazer escolhas na condição como vulnerável. Necessitar-se-ia criar o diálogo delicado entre a psicologia e o direito, bem como a ética diante das questões da guarda, visita, alienação parental e o conceito jurídico na interlocução entre essas áreas.

O higienismo é um fator de preocupação que ocorreu entre os governantes, relativos ao binômio saúde-doença, como um importante fenômeno social. Diante disso, foi observado que a posição da mulher de forma assimétrica a do homem, como figura dominante e detentora do pátrio poder ocupou esse lugar, graças à emancipação feminina. Tais movimentos se somaram à corrente da medicina do século XIX e à própria valoração da família nuclear dentro do segmento da política estatal em um paralelo às famílias burguesas. Uma vez que tais famílias burguesas eram dominadas pelo pátrio poder, focado na figura masculina como o provedor, o verdadeiro fiscal da família. Essa assimetria predominante entre mulher e filhos submissos ao pátrio poder transformava o casamento civil em um elo indissolúvel. A considerar o próprio código civil de 1916 que, através de sua regulação, primava para importância das questões ligadas à falta conjugal e não ao bem-estar da criança como foco principal.

por outro lado, como se consideraria a interseção da família sendo um degrau cultural, somando indivíduo e comunidade, como um marco evolutivo da sociedade? Nessa constituição, evidenciam-se os termos jurídicos com as ciências sociais e os diversos marcos teóricos do direito em conformidade a visão interdisciplinar. No campo do direito, as várias transformações e efeitos do fim da conjugalidade nas relações familiares e a questão da guarda dos filhos nas separações e divórcios podem ser objetos de estudo, não somente no campo das ciências sociais, mas também nas inovações no diploma do Processual Civil, como exemplo, abrigado no capítulo X Das Ações De Família, a partir do artigo 693 e seu parágrafo único e seguinte. Essa novidade atende, no geral, a uma questão quando se trata da lide de Direito de Família, onde a processualista assume certas peculiaridades, pela necessidade de adequação e importante preferência pela solução consensual primada. Atualmente, com os dispositivos elencados no NCPC, se busca responder a toda essa necessidade, por meio do supracitado artigo e as normas abrigadas no referente capítulo, tais como: ações de divórcio, separação, reconhecimento, extinção da união estável, guarda, visitação e filiação.

Segundo Wambier et al. (2015), o legislador elencou dentre as ações; quais se aplicariam as normas do capítulo $X$, nas de separação. Houve uma opção do NCPC, depois de muitos debates conforme a corrente doutrinária, por entender 
a existência da separação judicial. A quem entenda, todavia, que existe, única e exclusivamente, como forma de dissolução do casamento, e não apenas da sociedade conjugal, o divórcio. Paulo Luiz Netto Lobo apud Wambier et al. (2015), descreveu que:

Agora, com o desaparecimento da tutela constitucional da separação judicial cessaram a finalidade e a utilidade da dissolução da sociedade conjugal, porque esta está absorvida inteiramente pela dissolução do vínculo não restando qualquer hipótese autônoma. Por tais razões perdeu sentido o caput do artigo 1571 do Código Civil de 2002, que disciplina as hipóteses de dissolução da sociedade conjugal: morte, invalidade do casamento, separação judicial e divórcio. Excluindo-se a separação judicial, as demais hipóteses alcançaram diretamente a dissolução do vínculo conjugal ou casamento; a morte, a invalidação e o divórcio dissolvem o casamento e fortiori a sociedade conjugal

... Esse entendimento encontra ressonância em decisões mais recentes: TJSP, AI 0357301-80.2010.8.26.0000, 8.a Câm. Dir. Priv., j.10.11.2010, v.u., rel. Des. Caetano Lagrasta, DJe 16.11.2010; Apl. 568131, 2.a T.Cív., j.29.02.2012, v.u., rel. Des. Sérgio Rocha, DJe 02.03.2012; TJMG, Apl. 1.0487.06.021825-1/001, 4.a Câm. Cív., j.20.01.2011, v.u., rel. Des. Dárcio Lopardi Mendes, DJe 07.02.2011. .(WAMBIER,2015, p.59)

Ainda segundo a autora Wambier et. al. (2015), o NCPC faz referência à separação e não esvazia os argumentos da corrente doutrinária que hoje prevalece. Subsidiariamente, se aplicam essas normas às ações de alimentos e as que versam sobre os interesses das crianças e dos adolescentes. Com o enfoque na aplicabilidade legal da mediação. Conforme a inteligência do artigo 696 do NCPC, o legislador já prevendo a extensão do processo de mediação, possibilitou que este fosse dividido em várias sessões, tantas quantas fossem necessárias, conforme é a própria natureza da mediação em respeitar o tempo de cada pessoa envolvida.

De acordo com Bueno (2015) admitiu-se que as audiências fossem realizadas em diversas sessões, sem prejuízo de serem adotadas as providências para evitar o perecimento de direito e afinou-se com o art. 695 do referido diploma e se relacionou intimamente com a razão de ser da busca de soluções mediadas de conflitos. Frustradas as tentativas de solução consensual do conflito, observar-se-á o procedimento comum, a partir do art. 335, isto é, abrindo-se para o réu a oportunidade de apresentar sua contestação cujo prazo variará de acordo com as diversas hipóteses reguladas nos incisos e nos parágrafos daquele dispositivo. A diversificação dos profissionais que atuam nas "ações de família" 
é fundamental para se atingir os objetivos desejados desde o direito material, inclusive; mas, não só para fins de obtenção de solução consensual do conflito, tão enfatizada pelo NCPC em geral e, em específico, pelo procedimento especial.

\section{ANTECEDENTES HISTÓRICOS DA MEDIAÇÃO E A SUA APLICABILIDADE NO ÂMBITO FAMILIAR}

A mediação é um tema relativamente novo no mundo jurídico brasileiro, remontando ao ano de 1998. A primeira iniciativa de institucionalização da mediação no contexto jurídico nacional partiu da então Deputada Federal pelo Estado de São Paulo Zulaiê Cobra Ribeiro. O Projeto de Lei (PL) recebeu o número 4.827/98 na Câmara dos Deputados. A principal característica desse projeto foi à institucionalização de um procedimento não obrigatório, que poderia ser instaurado antes ou no curso do processo judicial, desde que a matéria versada admitisse conciliação, reconciliação, transação ou acordo de outra ordem.

Em seguida, o mesmo PL recebeu aprovação pela Comissão de Constituição e Justiça, tendo sido enviado ao Senado Federal sob o número Projeto de Lei da Câmara (PLC) 94/2002 da referida Deputada Federal à época. Os trâmites legislativos percorridos por esse projeto foram os seguintes: Projetos de Leis do Senado (PLS), a saber: PLS 517/2011, que instituiu e disciplinou o uso da mediação como instrumento de prevenção e solução de conflitos; PLS 405/2013, dispõe sobre a mediação extrajudicial; PLS 434/2013 que dispõe sobre a mediação e o PL 7.169/2014 do Senado Federal que se originaram do PLS 517/2011. A transformação na Lei da Mediação se deu pela Lei Ordinária de número 13.140/2015.

O importante marco histórico e regulatório da mediação judicial no Brasil ocorreu consoante ao PL número 8.046/2010 (PINHO, 2008), cujos artigos sobre mediação compuseram a Emenda Aglutinativa Global aprovada na Câmara dos Deputados no ano de 2013 que abrangeu os demais Projetos de Lei. Notado como um novo paradigma processual, de forma mais efetiva a partir do PLS número 166/2010, este envolveu muitas inovações legislativas, a iniciar pelas novas tendências do NCPC, em destaque a mediação e as formas alternativas de resoluções de conflitos no referido diploma (VASCONCELOS, 2014).

A aplicabilidade legal da mediação familiar descreve que o Estado veda aos sujeitos de Direito realizarem, com suas próprias mãos, a justiça, assumindo a função de prestar a tutela jurisdicional, ou seja, a atribuição de dirimir os conflitos existentes, objetivando, imediatamente, aplicar a lei ao caso concreto e, em caráter imediato, restabelecer a paz entre os litigantes e consequentemente 
manter a estabilidade social. Mas para que o Estado possa prestar a tutela jurisdicional, ele se cerca de regras processuais para exercer tal função, aplicando, assim, a lei material. Tais regras devem propiciar a melhor forma a aplicação da norma material e tem como finalidade social o reconhecimento pela sociedade.

Infelizmente, se verifica hoje, no Poder Judiciário, que ainda há discussão da violência doméstica. Esta abrange não só as famílias abastadas, mas de todas as classes sociais, isso demonstra que tal fenômeno não se associa ao estado de pobreza, e sim a questões internas: falta de limites, baixa autoestima, indefinição de papéis, ausência de informação, orientação no que concerne direitos e deveres, e, ainda, ao não entendimento das normas jurídicas que regem as vidas dos envolvidos no ato da formação da família.

A modificação dos valores e culturas, intolerâncias, sexismo, somados a multiplicidade de fatores sociais e econômicos, por exemplo, dão origem a um fenômeno que percorre com rapidez todos os segmentos da sociedade: a violência. Rotineiramente, ela é resultado de ocorrências, cada vez mais generalizadas e abrangentes no seio familiar; atingindo mulheres, crianças e adolescentes. Isso aumenta cada vez mais no judiciário o volume de ações litigiosas cultuados ainda por uma forma cultural popular arcaica, deitada nas bases da sentença prolatada pela figura do juiz. Onde as partes em litígio na maioria das vezes buscam esta sentença como uma forma de vingança.

De acordo com PINI (2003), o desconhecimento do cidadão de seus direitos e deveres, por vezes, o induz a ferir regras do convívio familiar; que traz consigo consequências graves como rejeições e atitudes de negação aos direitos mais básicos do ser humano, tais como: o não reconhecimento da paternidade, a não prestação de alimentos e as visitações à prole. Esses atos o colocam, ainda, em uma posição constrangedora, inclusive por agressões físicas e mentais sofridas pela própria prole e mulheres.

Na busca de uma solução para esse problema, que não se limita à figura do Estado; via judiciário, procura-se intervir nas relações humanas não ao aplicar o Direito ao caso concreto, mas atuar nas esferas preventivas, em meio à efetivação de políticas públicas sociais vinculadas ao âmbito familiar, de modo a ofertar, viabilizar através de suas ações e seus programas eficazes e capazes a abrigar todos os componentes do tecido social em uma visão tridimensional do indivíduo - família - comunidade. Esse conjunto de ações do Estado conjuga, dessa forma, o acesso à justiça e à cidadania na garantia de suas práticas próprias a manter, estimular e difundir a integridade do trato social, administrando, por meio do tratamento adequado da solução de conflitos pelo instituto da mediação familiar. Dessa forma, reduzir-se-ia as margens de erros da repetitiva submissão aos entraves impostos pelo formalismo. É inegável e vital o respeito à regra da 
preservação familiar unido à garantia líquida e certa da aplicação das normas por todas as esferas do Poder Legislativo, ligadas ao contexto sócio-político.

As famílias permaneceriam em razão dos filhos havidos, e dessas relações por motivos do comprometimento, do envolvimento dos progenitores em continuar a plenitude do exercício do poder - dever familiar, independente da continuidade ou não do casamento. Portanto, tais premissas teriam como finalidade almejada, a permeabilidade e a função do vínculo na garantia da família ao prevalecer o melhor interesse das crianças e dos adolescentes.

\section{DO NOVO PARADIGMA: O DIREITO E A MEDIAÇÃO DE FAMÍLIA}

Mediante as transformações sofridas no próprio processo da evolução social e, por conseguinte, no seio familiar, a ciência do Direito tende com a modernidade a ser compreendida de modo racional e presente no debate jurídico como uma justiça material. Nessa duplicidade dimensional observa-se harmonia ao novo paradigma da ciência, que é a transformação do entendimento entre os opostos do ser e "dever/ser" na situação fática na qual resulta nos fatos jurídicos diante da norma e da realidade.

Consoante às novas tendências observadas, o objeto do direito abrange, simultaneamente, os fatores da realidade do conflito e o texto normativo, que constituem, conjuntamente, a normatividade jurídica circular; os valores da realidade concebidos com o âmbito material da norma; e a ideia normativa orientadora, concebida como programa da norma. A mediação de conflitos, enquanto trato intersubjetivo e transdisciplinar, possuem métodos empíricos, facilitadores do encontro de soluções consensuadas, legítimas, mas que precisam ser compreendidas, interpretadas e decididas no âmbito de um sistema jurídico, necessariamente democrático. A mediação dignifica e humaniza os processos de solução de disputas, vistos, na perspectiva positivista, como técnicas de uma metodologia dogmática e formal (VASCONCELOS, 2014).

Nestes desafios surgidos na contemporaneidade, a mediação vem ocupar um papel de destaque e também como uma ferramenta preciosa na solução de conflitos familiares. Ela traz consigo inúmeros benefícios para causas que no sistema tradicional de justiça levaria anos, pois facilita e promove o diálogo ao cuidar das questões de caráter e afetivos das pessoas, uma vez que promove a inserção no contexto profissional do mediador como um terceiro neutro imparcial que oferta as partes uma solução benéfica e consensual a todos os envolvidos que, em muitas vezes, abrigam vínculos mais profundos, tais como os familiares. A mediação familiar visa aperfeiçoar nas famílias um aspecto fundamental da preservação da comunicação e preparar os envolvidos no conflito a novos relacionamentos, ao atuar de um modo preventivo e profilático sem a repetição de antigos erros do casamento dissolvido. 
Assim, a mediação prepara a família envolvida no conflito para um enfrentamento menos traumático, menos sofrível, a tirar proveitos positivos. Diante da realidade das famílias, se pode observar que neste processo de evolução dentro da própria civilização existem bases solidificadas da sociedade formadas pela família tradicional e a notória preocupação estatal em agir como um sujeito por meio de medidas protetivas e norteadoras de regras para manter a família através de leis que garantam a ordem social. Porém, na contemporaneidade da família tradicional, como já foi revelada, somente a preocupação do cuidar na esfera patrimonial, não atenta para a esfera da afetividade das pessoas. $\mathrm{O}$ que era antes somente uma preocupação do direito tradicional de família, como a divisão de bens das pessoas ao fim do casamento, passou a estimar a unidade familiar os seus interesses comuns pessoais da própria família (TOALDO e OLIVEIRA, 2011).

Segundo Grinover (2015), no Brasil, as instituições foram desenhadas de tal forma a possuírem uma boa função, mas ainda carecem de planejamento, acompanhamento e execução para sua finalização. Isso se faz pela necessidade de incluir critérios revisionais e até mesmo de suporte para melhores caminhos. A importância e o desenvolvimento do ato de institucionalizar não estão restritos somente pela norma, vislumbrando para a mediação um futuro promissor, mas irão depender principalmente da seriedade como são aplicadas, desenvolvidas e envolvidas na disseminação das políticas públicas bem como a sua aceitação e a vontade como essas políticas serão empregadas.

\section{Considerações Finais}

Diante do exposto neste trabalho, pôde-se perceber que a mediação familiar vem somar procedimentos acessíveis à população civil, no âmbito de suas demandas assistidas no que tange a solução dos conflitos familiares. O seu regramento pelo NCPC e pela Lei da Mediação permitiu uma acessibilidade à justiça de forma plena, célere ao favorecer o tecido social brasileiro um novo, amplo e fértil caminho democrático.

Contudo, diante de todas essas transformações, que estão ora ocorrendo no cenário brasileiro e mundial, se faz necessária a mudança da cultura, não somente das classes sociais, mas também de todos os operadores do direito, bem como dos segmentos afins. Isso se faz por uma transformação da cultura da sentença de origens arcaicas, de um sistema que para haver um ganhador, tem que ter tradicionalmente um perdedor. A utilização da mediação familiar traz consigo consequências positivas e modernas dessa integração, como a economia de tempo e pecuniária e, principalmente, a prevenção de desgastes emocionais e 
psicológicos que envolvem todos os interessados nas questões familiares e sociais. Tais iniciativas descritas são bem vistas pela Ordem.

Outra conclusão que se pôde extrair é que através da popularização da mediação como um todo e da mediação familiar mais especificamente, estas propiciarão uma mudança de paradigma na cultura do litígio em nossa sociedade por abolir o costume do contencioso. Por fim, a mediação familiar assume um papel democrático, permeável, flexível, por dissolver o determinismo referencial, e se abrir para implantação de novas políticas públicas mais eficazes e capazes de ofertar a mediação no plano familiar, de modo a valorizar mais as referências socioafetivas e a preservação da família e da ordem social. Uma vez que esta objetiva os melhores interesses à autonomia, à cidadania, ligados à democracia e aos direitos mais básicos do ser humano.

As conclusões descritas neste trabalho também vêm ao encontro com o preconizado por Watanabe (2011) que descreveu que a sociedade brasileira assistiria com toda certeza uma profunda transformação da atual cultura da sentença pela cultura da pacificação que favoreceria o nascimento de uma maior coesão social.

\section{Referências}

BUENO, Cassio S. Novo Código de Processo Civil Anotado. São Paulo: Ed. Saraiva, 1aed., p. 433-437 e p. 454-457, 2015.

Constituição Da República Federativa do Brasil, 1988.

CUCONATO, Paulo. A Mediação e a Descrição do seu Caminhar no Processo Legislativo. Rio de Janeiro: Dissertação de Mestrado, Universidade Estácio de Sá, 212p. 2016.

DUARTE, Lenita P. L. Uma Interlocução da Psicanálise com o Direito. A Guarda dos Filhos na Família em Litígio - Uma Interlocução da Psicanálise com o Direito. Rio de Janeiro: Ed. Lumen Juris, 4를. ed., p. 115-121, 2012.

DURKHEIM, Émile. Violência e condição social: o homem é feito do meio? Boletim Jurídico, Ano III, nº 126, Ed. Minas Gerais. 
CUCONATO, P.; SANTOS, D,M.. Uma interlocução direito de família com a mediação de conflitos no acesso à justiça.

GARCIA, Vander. Super Revisão OAB Doutrina Completa. Indaiatuba: Ed. Foco, 2a ed., p. 429-432, 2013.

GONÇALVES, Carlos R. Direito Civil Brasileiro - Direito de Família. São Paulo: Ed. Saraiva, 7a ed., p. 17-32, 2010.

GRINOVER, Ada P. Cultura da Conciliação no Brasil Não Depende Só de Leis. In: Consultor Jurídico (entrevista), nov., 2015. Disponível em: <http://www.conjur.com.br/2015-nov-27/cultura-conciliacao-nao-depende-leisada-pellegrini $>$, acessado em 2/12/2015.

PEREIRA, Caio M. da S. Instituições de Direito Civil. Rio de Janeiro; Ed. Forense, 14a ed., v. 5, 2004.

PINHO, Humberto D. B. O Novo CPC e a Mediação - Reflexões e Ponderações. Disponível em: < http://www2.senado.leg.br/bdsf/item/id/242895> 2008, acessado em 10/07/2015.

PINNI, DÉBORAH K. Da Aplicabilidade Legal da Mediação Familiar. In: MUSZKAT, MALVINA E. (Org.) Mediação de Conflitos - pacificando e prevenindo a violência. São Paulo: Ed. Summus, 3ạ ed., p. 43-47, 2003.

RIZZARDO, Arnaldo. Direito de Família. Rio de Janeiro: Ed. Forense, 2a ed., 2004. TOALDO, Adriane M. e OLIVEIRA, Fernanda R. Mediação Familiar: novo desafio do Direito de Família Contemporâneo. In: Âmbito Jurídico, Rio Grande, XIV, n. 95, dez 2011.Disponível em $<$ http://www.ambitojuridico.com.br/site/?n link=revista artigos leitura\&artigo $\underline{\mathrm{id}=10860 \& \text { revista } \text { cadero }=21}>$ acessado em 29/07/2016.

VASCONCELOS, Carlos E. Mediação de Conflitos e Práticas Restaurativas. Rio de Janeiro: Ed. Método, 3a ed., 295p., 2014.

WAMBIER, Teresa A. A.; CONCEIÇÃO, Maria L. L.; RIBEIRO, Leonardo F. da S. et al. Primeiros Comentários ao Novo Código de Processo Civil - artigo por artigo. São Paulo: Ed. Revista dos Tribunais, 1aㅡ. ed., p. 1028-1032 e p. 1076-1080, 2015. 
CUCONATO, P.; SANTOS, D,M.. Uma interlocução direito de família com a mediação de conflitos no acesso à justiça. R. Científica UBM - Barra Mansa (RJ),

ano XXIII, v. 20, n. 39, 2. Sem. 2018. Págs 96-111.

ISSN 1516-4071

WATANABE, Kazuo. Política Pública do Poder Judiciário Nacional para Tratamento Adequado dos Conflitos de Interesses. In: Revista de Processo (REPRO) - São Paulo: ano 36, n. 195, maio, p. 381-389, 2011. 